\title{
SENTENCIAS Y AUTOS DEL TRIBUNAL SUPREMO Y RESOLUCIONES DE LA DIRECCION GENERAL DE LOS REGISTROS EN QUE SE CITAN, ESTUDIAN O APLICAN PRECEPTOS CONSTITUCIONALES (Abril-mayo 1980)
}

\author{
POR \\ ENRIQUE LINDE PANIAGUA \\ Universidad Nacional de Educación a Distancia
}

\begin{abstract}
SUMARIO
1. Repertorio de sentencias, autos y resoluciones por orden cronológico con transcripción de sus Considerandos básicos acompañados de un comentario y bibliografía sobre cada tema: A) Sentencias y autos del Tribunal Supremo; B) Resoluciones de la Dirección General de los Registros.
\end{abstract}

\section{REPERTORIO}

A) Sentencias $y$ autos del Tribunal Supremo

Núm. 2. Sentencia de 21 de abril de 1980. Contencioso-Administrativo. Sala III. Ponente, J. Pérez Fernández (Repertorio Aranzadi 1.392/1980): ARTICULOS 3, 27, 53.2 DE LA CONSTITUCION.

\section{Derecbo a la educación}

Se quebranta el derecho fundamental a la educación, hasta el límite máximo de negarlo del modo más absoluto, cuando la enseñanza se imparte en un idioma, desconocido por el destinatario de la enseñanza, distinto de la oficial lengua española.

\section{Antecedentes}

Al artículo 53 de la Constitución se refieren las sentencias n.0 6, 7 y 8 del Repertorio de 1979 (véase esta misma Revista, n. ${ }^{\circ}$ 6), si bien en los supuestos a que aludimos no se plantea el problema que se suscita en la sentencia comentada.

Por lo que se refiere al artículo 27 de la Constitución, la sentencia n.$^{\circ} 9$ del Repertorio de 1979 (véase esta misma Revista, n. ${ }^{\circ}$ 6) hace algunas consideraciones en lo relativo a la compatibilidad del principio de libertad de creación de centros docentes y el control del Estado en el marco de una programación de carácter general de la enseñanza, que se encuentran reflejados en la sentencia de 21 de abril de 1980 que comentamos. Sin embargo, mientras que en aquella ocasión el Tribunal Supremo sustentaba la tesis de que el artículo 27 era de carácter programático, ahora lo considera de aplicación directa, si bien no hay 
identidad de supuestos base, por lo que no es posible estimar la contradicción entre ambas doctrinas.

Considerando: Que la sentencia objeto del presente recurso de apelación declara la inadmisibilidad del contencioso-administrativo deducido por violación de un derecho fundamental de la persona, basando tal declaración de inadmisibilidad - expresado ahora esencial y resumidamente- en la circunstancia de que acogido el demandante a las previsiones de la Ley de 26 de diciembre de 1978, instauradora de un especial y sumario procedimiento en esa vía contencioso-administrativa - amén de hacerlo también en lo atinente a lo penal y a lo civil-, sólo son subsumibles en ese cauce procesal las pretensiones que se deduzcan so pretexto de violación de derecho o libertades expresamente catalogados de la precitada Ley de 1978 (artículo 1.2), comprensivo de una relación cerrada, únicamente ampliada mediante el Real Decreto de 20 de febrero de 1979 (artículo único), sin que ni en una ni en otra se haga referencia alguna al derecho a la educación, proclamado en el artículo 27 de la Constitución española, que es precisamente el que, como básico, invoca el actor como soporte jurídico de su pretensión.

Considerando: Que ciertamente, en determinado momento cronológico, el razonamiento que antecede, crucialmente incluido en la cuidada sentencia de instancia, pudo ser jurídicamente irreprochable, mas es de notar que, a criterio de esta Sala de apelación, la promulgación y vigencia de la Ley Orgánica 2/1979, de 3 de octubre, del Tribunal Constitucional, vino a suponer una alteración en este punto ya delimitado referente a las posibilidades de orden procesal para la protección jurisdiccional de los derechos fundamentales de la persona, desde el momento que en tal Ley - que posee la condición de orgánica - no es que se contenga precepto o disposición limitativa en cuanto a cuáles sean los derechos o libertades protegibles, sino que de modo expreso, en su disposición transitoria $2{ }^{a}$, punto 2 , se establece que persistiendo - siquiera provisionalmente- como vía judicial previa al recurso constitucional de amparo la configurada en la Ley de 26 de diciembre de 1978, a los efectos de la adecuada protección jurisdiccional, el ámbito de la misma se entiende extendido a todos los derechos y libertades a que se refiere el artículo 53.2 de la Constitución, de acuerdo con el cual, cualquier ciudadano podrá recabar la tutela de las libertades y derechos reconocidos en el artículo 14 y la sección 1 del capítulo $2 .^{\circ}$ ante los tribunales ordinarios, por un procedimiento basado en los principios de preferencia y sumariedad $y$, en su caso, a través del recurso de amparo ante el Tribunal Constitucional.

Considerando: Que el hecho de que tanto en el momento de ejercitarse la acción por el demandante como en la actualidad no haya tenido lugar la constitución del Tribunal creado por nuestra primera Ley, no puede determinar la inaplicabilidad de los preceptos de la Ley Orgánica del mismo, de 3 de octubre de 1979 - - en lo que ahora interesa - porque esa demora no viene impuesta de modo expreso por el texto de que se trate, de lo que se infiere la tesis que sustentamos $y$, más todavía, no parece que deba ser otra la solución, desde el punto en que ha previsto el legislador (disposición transitoria 2.a núm. 1) que los plazos previstos en la misma Ley para interponer el recurso de amparo comenzarán a contarse desde el día en que quede constituido el Tribunal, cuando las resoluciones o actos que originen el recurso fueran anteriores a aquella fecha y no hubieran agotado sus efectos, previsión o supuesto que puede convenir al de autos, por lo que ha de reputarse que nada obsta a que -ínterin se constituye el Tribunalpuedan agotarse por los interesados las vías judiciales que imperativamente le son impuestas por la normativa como previas para aguardar en su caso, y si así con- 
viene a los legitimados al efecto, el momento de funcionamiento del Tribunal Constitucional, con el consiguiente inicio en el cómputo del plazo para recurrir en vía de amparo y, efectivamente, hacerlo.

Considerando: Que, tanto en la vía administrativa inicial como en la jurisdiccional, concreta el actor la violación de los derechos fundamentales en el de la educación, que tiene su soporte en el artículo 27 de la Constitución, pudiendo destacarse - a los fines del actual recurso- lo incluido en los números 1, 2, 5 y 8 de tal norma que proclama el derecho que todos tienen a la educación la que tiene por objeto el pleno desarrollo de la personalidad bumana en el respeto a los principios democráticos de convivencia y a los derechos y libertades fundamentales, garantizando los poderes públicos el derecho de todos a la educación, e inspeccionando y bomologando el sistema educativo para garantizar el cumplimiento de las leyes, no obstante lo cual el competente órgano administrativo al que se dirigió formalmente el interesado, como padre y legal representante del alumno afectado desatendió la solicitud deducida como consecuencia de impartirse las clases de varias asignaturas en el Instituto Nacional de Bachillerato de que se trata exclusivamente en catalán, con textos en el mismo idioma, pese a existir en el expediente administrativo informe emitido por el inspector jefe de Enseñanza Media del Distrito Universitario, expresivo de que el Instituto en cuestión no está legalmente autorizado para impartir las enseñanzas en lengua catalana, sin que haya solicitado la reglamentaria autorización para cambiar los libros de texto utilizados en el pasado año académico de 1978-79, con la consecuencia, en el sentir de la propia Inspección, de que todo estudiante del citado centro tiene derecho a pedir se expongan las materias (oralmente o por escrito) en lengua castellana.

Considerando: Que no parece sea menester mucbos razonamientos para concluir que por supuesto con absoluto respeto también de otros mandatos constitucionales, como puedan ser los del artículo $3 .^{\circ}$, expresivo de que todos los españoles tienen el deber de conocer y el derecbo de usar del castellano como lengua española oficial del Estado, siendo también oficiales en las respectivas comunidades autónomas, de acuerdo con sus Estatutos, las demás lenguas españolas, se quebranta el fundamental derecho a la educación, incluso cabe decir que basta el máximo limite de negarlo del modo más absoluto, cuando la enseñanza se imparte en un idioma distinto de la oficial lengua española desconocido aquél por el destinatario de la enseñanza, sin que nada de lo firmado, ni de cuanto se razona en esta sentencia, vaya, ni de cerca ni de lejos, contra el respeto que por un igual merecen las demás lenguas españolas en todas sus posibilidades, incluida por supuesto la de su utilización en las comunidades autónomas a satisfacerse el derecho a la educación que a su vez asiste a quienes las conocen.

Considerando: Que por todo lo expuesto procede la estimación del recurso de apelación, con estimación igualmente del recurso contencioso administrativo, bien que con carácter parcial, toda vez que no es atendible la petición relativa al derecho del hijo del actor a ocupar plaza en el Instituto en cuestión, punto que no consta ni siquiera puesto en discusión en vía administrativa, ni atender otras peticiones extrañas al ámbito en que este proceso ha de desenvolverse, cuales las de apertura de expedientes disciplinarios y condena a indemnización de daños y perjuicios, sin especial pronunciamiento en cuanto a costas, atendidas las previsiones del artículo 10.2 de la Ley de 26 de diciembre de 1978, y 131 de la Ley Jurisdiccional. 


\section{Comentario}

La sentencia de 21 de abril de 1980 que comentamos tiene dos partes claramente diferenciadas. Los considerandos 1,2 , y 3 se refieren a la aplicación al derecho a la educación del procedimiento previsto en la Ley de Protección jurisdiccional de los Derechos Fundamentales de la persona de 26 de diciembre de 1978, mientras que los considerandos 4, 5 y 6 de la sentencia trazan algunos perfiles del derecho a la educación consagrado en el artículo 27 de la Constitución en relación al artículo 3 del mismo texto fundamental.

1. El razonamiento que ocupa los considerandos 1,2 y 3 de la sentencia es irreprochable. En efecto, la Ley Orgánica del Tribunal Constitucional (L.O.T.C.) amplió en su disposición transitoria segunda el ámbito de aplicación de la Ley de Protección jurisdiccional de 26 de diciembre de 1978, de modo que quedaban protegidos por entero los derechos y libertades a que se refiere el artículo 53.2 de la Constitución. Protección que comienza desde el momento de la entrada en vigor de la L. O.T.C. con independencia de la fecha de constitución del Tribunal. A mayor abundamiento de la tesis de la sentencia, hemos sostenido anteriormente (véase E. Luide, La instauración del principio de igualdad entre Administración pública y particulares en el proceso contencioso-administrativo, en «Revista Española de Derecho Administrativo», núm. 23, 1979, págs. 567 a 571) que aun con anterioridad a la promulgación de la L. O. T. C., la exclusión de una serie de derechos de la protección de la Ley de 26 de diciembre de 1978, operada en el artículo 1 de la misma, era de dudosa constitucionalidad, en cuanto que el legislador ordinario no está facultado para reducir un ámbito de protección determinado para una serie de derechos cuando la Constitución sin excepción alguna los contempla, cual es el tenor del artículo 53.2 de la norma fundamental.

2. Mayor trascendencia tienen los considerandos 3, 4 y 5 de la sentencia. El considerando 3. Constitución, en el sentido de que los poderes públicos son responsables en cuanto que garantizadores del derecho a la educación, en los precisos términos en que se expresan los referidos apartados del artículo 27 de la Constitución. Por ello, la solicitud del padre en cuanto representante legal del alumno afectado por la impartición de algunas clases en lengua catalana, dirigida al órgano administrativo competente, es procedente, sobre todo teniendo en cuenta que el Centro en donde se impartían dichas asignaturas en lengua catalana no estaba autorizado para ello, por lo que no es dudoso el derecho del alumno afectado a recibir la enseñanza en lengua castellana.

Parece incuestionable que la decisión de impartir las enseñanzas con carácter general o singular en las demás lenguas españolas no puede ser sino el resultado de una decisión que se sitúa en un nivel diferente al de los enseñantes o las autoridades de los Centros docentes, entre otras razones porque si los poderes públicos son los que garantizan el ejercicio del derecho a la educación, sólo éstos pueden, en una adecuada planificación, garantizar el derecho de conocer y el derecho a usar por todos los españoles el castellano y hacer esto compatible con la enseñanza en las demás lenguas españolas.

En el caso que nos ocupa resulta evidente que la utilización de la lengua catalana no tenía justificación alguna, lo que determina al Tribunal Supremo a pronunciarse tajantemente, hasta el punto de considerar que se quebranta el derecho fundamental a la educación hasta el límite máximo de negarlo en el modo más absoluto, cuando la enseñanza se imparte en un idioma desconocido por el destinatario de la enseñanza, distinto de la oficial lengua española. Pero seguirá diciendo la sentencia que nada de lo afirmado va «contra el respeto que por igual merecen las demás lenguas españolas en todas sus posibilidades, incluida por supuesto la de su utilización en las Comunidades autónomas a satis. facerse el derecho a la educación que a su vez asiste a quienes las conocen». Sin embargo, no explica la sentencia cómo pueden conciliarse estos derechos, lo que no parece aventurado predecir será fuente de conflictos, no sólo por las dificultades que entraña desde la perspectiva de las posibilidades materiales de satisfacer los intereses en juego, sino por la problemática compartición de competencias en la materia entre el Estado y las Comunidades autónomas (véase la Ley Orgánica 5/1980, de 19 de junio, por la que se regula el Estatuto de Centros Escolares, especialmente la disposición adicional tres. Asimismos los Estatutos de Autonomía vasco, artículo 16, y catalán, en su artículo 15).

En el Tribunal Constitucional está pendiente un recurso de inconstitucionalidad inter- 
puesto cotra la citada Ley Orgánica 5/1980, cuya resolución puede dar luz sobre algunos de los muchos problemas que suscita la comprensión del conjunto de normas referidas.

\section{Núm. 3. Auto de 2 de mayo de 1980. Criminal. Ponente, L. Vivas Marzal (Re- pertorio Aranzadi núm. 1.917): ARTICULOS 18.1, 117.5 DE LA CONSTITUCION.}

\section{Principio de unidad jurisdiccional}

La jurisdicción ordinaria es la competente para conocer los delitos contra el honor de la Guardia Civil a tenor de lo dispuesto por la Constitución en su artículo 117.5 y la Ley de Protección jurisdiccional de 26 de diciembre de 1978.

Considerando: Que para la adecuada resolución de cualquier conflicto jurisdiccional en el que surgen fundadas dudas sobre la determinación de la jurisdicción competente para el enjuiciamiento de determinadas conductas punibles, se ban de tener en cuenta dos principios fundamentales $y$ de superior rango: el de la unidad jurisdiccional, proclamado en el número 5 del artículo 117 de la Constitución, el cual conlleva la expansión de la jurisdicción ordinaria y el constreñimiento de las jurisdicciones especiales y excepcionales, las que sólo serán competentes cuando les corresponda el conocimiento para enjuiciar bechos punibles merced a preceptos legales claros, expresos y terminantes; y el emanado del artículo 3.1 del Código Civil, conforme al cual las normas se interpretarán acudiendo no sólo a los tradicionales métodos gramatical, lógico, histórico y sistemáticos, sino también al sociológico - realidad social del tiempo en que han de ser aplicadas-, y de manera fundamental al teleológico -espíritu y finalidad de dichas normas.

Considerando: Que, a los solos efectos de la resolución del presente conflicto, es preciso recordar que los hechos que determinaron la incoación de la causa fueron los siguientes: en $M$., con motivo de sus fiestas patronales, en una caseta montada por C.S.U.T., un paisano, componente de un conjunto músico-vocal que actuaba esa noche -la del 3 a 4 de agosto de 1978-, en el momento de iniciar su actuación, se dirigió por el micrófono al público asistente diciendo: «Se abre esta actuación en conmemoración del caso que ocurrió en $\mathrm{C}$. y en que actuaron los criminales de la Guardia Civil»; como consecuencia de estos hechos, intervino la jurisdicción militar de la 2. a Región, entendiendo que los mismos constituían un delito incardinado en el artículo 317 del Código de Justicia Militar -injurias $\mathrm{u}$ ofensas a los Ejércitos o a Instituciones, Armas, Clases o Cuerpos determinados de los mismos-, cuyo enjuiciamiento, sea cualquiera la persona responsable, corresponde a los tribunales militares por virtud de lo dispuesto en el número 2 del artículo 6 de dicho Código. Radicando ahora la cuestión en determinar si esa competencia, indiscutible al tiempo de perpetración de los hechos, ha variado y corresponde a los tribunales militares por virtud de lo dispuesto en el número 2 del normas siguientes: artículo 117.5 de la Constitución; artículo 5.1 , párrafo $2 .^{\circ}$, de la Ley de Policía de 4 de diciembre de 1978, y artículo 2 y disposición transitoria 2.a de la Ley de Protección Jurisdiccional de los Derechos Fundamentales de la Persona, de 26 de diciembre de 1978, completada por el artículo único del Decreto de 20 de febrero de 1979.

Considerando: Que el inciso $2 .^{\circ}$ del número 5 del artículo 117 de la Constitución establece que «la ley regulará el ejercicio de la jurisdicción militar en el ámbito estrictamente castrense $y$ en los supuestos de estado de sitio, de acuerdo con 
los principios de la Constitución», suponiendo este precepto un mandato para que en el futuro se dicte una ley que regule esta materia conforme a las directrices emanadas de la Constitución, acentuándose asi, y puesto que ella misma lo previene, el carácter meramente programático o de declaración de principios que suelen tener los textos constitucionales, y que precisa para su aplicación y efectividad del adecuado desarrollo legislativo, el que en este caso todavia no se ba efectuado, aunque se balla en preparación. Infiriéndose de lo dicho que, no derogado o modificado todavía el Código de Justicia Militar, no puede sostenerse que lo ba reemplazado o recortado el número 5 del artículo 117 citado.

Considerando: Que la Ley de Policía de 4 de diciembre de 1978, en su artículo 5.1 , párrafo $2 .^{\circ}$, prescribe que «la Guardia Civil tiene fuero militar, salvo en los delitos que se cometan contra sus miembros en el ejercicio de las funciones señaladas en esta Ley, de cuyo conocimiento será competente la jurisdicción ordinaria». Así, pues, de haberse producido los hechos de autos contra miembros concretos, contra personas individualizadas del Instituto Armado de la Guardia Civil que se hallaran en el ejercicio de las funciones a que se refiere la mencionada Ley, la competencia de la jurisdicción ordinaria para conocer y enjuiciar el delito de autos sería indiscutible, pero recayendo el agravio o la ofensa de modo genérico sobre el Instituto dicho, sobre la Benemérita como Cuerpo, por más que se reconozca que quien ofende al todo agravia también a los miembros de ese todo sobre quienes refluye el vilipendio, la competencia de la jurisdicción ordinaria, por el solo imperio de la Ley aquí estudiada, es más que dudosa, y no debe, por tanto, considerarse y declararse con apoyo en dicha norma.

Constderando: Que la Ley de 26 de diciembre de 1978 sobre Protección Jurisdiccional de los Derechos Fundamentales de la Persona, en su artículo 1.2, se refiere a los derechos de reunión, expresión y asociación, a los de libertad personal, inviolabilidad de domicilio y de correspondencia y a otros entre los que no figura el derecho al honor, estableciendo en su artículo 2 que los delitos y faltas cometidos contra los derechos fundamentales de la persona comprendidos en el ámbito de esta Ley serán juzgados por los jueces y tribunales de la jurisdicción ordinaria, añadiendo, en su disposición transitoria 2..$^{a}$, que los juzgados, tribunales y autoridades de cualquier orden y jurisdicción distintos de la ordinaria que estuvieran conociendo de delitos de la índole reseñada, se inhibieran inmediatamente a favor de la referida jurisdicción ordinaria. Como el D. de 20 de febrero de 1979 , en su artículo 1 , y cumpliendo la autorización concedida al Gobierno por la Ley analizada, incorporó al texto de la misma, entre otros, el derecho al honor, el cual gozará de la misma protección penal atribuida a la jurisdicción ordinaria, no resta más problema que el determinar si el honor a que se refiere el precepto es el individual correspondiente a las personas físicas o si puede extenderse también al de las personas jurídicas, cuerpos, instituciones, clases de Estado u organismos públicos o privados; derecho al honor éste que es reconocido unánimemente por la doctrina, y de modo palmario por el C. P., en el párrafo $3 .^{\circ}$ del artículo 467 , y por la Ley de 26 de diciembre de 1978, en su artículo 4.4, los cuales mencionan expresamente a las corporaciones y a las clases determinadas del Estado.

Considerando: Que el título I de la Constitución se denomina «de los Derechos y Deberes Fundamentales», sin que en él se distinga entre personas físicas $y$ personas jurídicas o entes colectivos, y en la sección $10^{a}$ del capítulo $2 .^{\circ}$ de dicho título, donde, en el artículo 24 se anuncia la protección judicial de tales derecbos, se babla de los derechos fundamentales y de las libertades públicas sin restringirlas al solo individuo, y aunque en la exposición de motivos del $D$. de 20 de febrero 
de 1979 se diga literalmente: «La Constitución ya en vigor proclama en la sección $1 .^{a}$ del capitulo $2 .^{\circ}$ del título I una serie de derechos y libertades individuales.» Es lo cierto que esa exposición, dado el rango inferior de la disposición que preludia, no puede prevalecer o predominar sobre el texto constitucional ni subvertir su contenido, cuyo texto, por lo demás, bien claramente indica que no son únicamente los derechos individuales los proclamados y tutelados, puesto que, en el artículo 16.1, se garantiza la libertad ideológica, religiosa y de culto de los individuos y de las comunidades, en el artículo 16.3, se refiere a las confesiones en el artículo 22, prescribe que las asociaciones sólo podrán ser disueltas o suspendidas en sus actividades en virtud de resolución judicial motivada, precepto que el artículo 34 bace extensivo a las fundaciones, en el artículo 27.6, se reconoce a las personas físicas y jurídicas la libertad de creación de centros docentes, en los números 7 y 8 de dicbo artículo 27, se alude a los centros docentes y en el número 10, a la autonomía de las Universidades y, finalmente, en el artículo 28.1, se reconoce el derecbo de los sindicatos a formar confederaciones y a fundar organizaciones sindicales internacionales $o$ afiliarse a las mismas.

Considerando: Que a virtud de todo lo expuesto, y especialmente de los principios enunciados al inicio de la fundamentación jurídica de esta resolución, visto que el honor a que se refiere la Ley de 1978, complementada por D. de 20 de febrero de 1979 , es tanto el honor individual como el honor de las personas jurídicas, organismos o clases determinadas del Estado, procede resolver el presente conflicto jurisdiccional negativo a favor de la jurisdicción ordinaria y dentro de ella al del Juzgado de Instrucción de Morón de la Frontera, a quien, con testimonio de esta resolución, se remitirán las actuaciones, comunicando lo resuelto al Excmo. Sr. Capitán General de la 2. ${ }^{a}$ Región Militar.

\section{Comentario}

El principio de unidad jurisdiccional proclamado en el artículo 117.5 de la Constitución no ha tenido eficacia inmediata en cuanto a la asunción por los órganos judiciales ordinarios de los todavía existentes «Tribunales especiales» o «jurisdicciones especiales», cuya existencia subsistirá al menos hasta la promulgación de la Ley Orgánica del Poder Judicial, que actualmente se tramita en el Congreso, si bien no hay impedimento técnico alguno para que las referidas «jurisdicciones» fueran liquidadas con anterioridad a la promulgación de la citada Ley Orgánica. Este, sin embargo, no es el caso de la jurisdicción militar, que se consagra en el texto constitucional y que desde el punto de vista orgánico rompe constitucionalmente el principio de «unidad jurisdiccional» del referido artículo 117.5 del texto fundamental.

A partir de las anteriores observaciones puede compartirse el criterio del Auto que comentamos, según el cual la jurisdicción ordinaria participa de un principio expansivo en relación a las demás, lo que sería aplicable a la jurisdicción militar en tanto que esta última se configura con carácter restrictivo. En este sentido, es posible entender vigente la Ley de 17 de julio de 1948 relativa a conflictos jurisdiccionales, aunque no puede descartarse otra solución en la futura legislación que venga a sustituir a la Ley de conflictos jurisdiccionales, en la actualidad derogada parcialmente o insuficiente.

Sin embargo, la competencia de la jurisdicción ordinaria frente a la jurisdicción militar, en el caso que ocupa al Auto, no se deduce ni de la aplicación directa del citado artículo 117.5 , al que se atribuye carácter programático, ni de la interpretación de la Ley de Policía de 4 de diciembre de 1978, sino que tiene lugar en base a la Ley de Protección jurisdiccional de 26 de diciembre de 1978. 
Núm. 4. Sentencia de 5 de mayo de 1980. Contencioso-Administrativo. Sala III. Ponente, J. L. Ruiz Sánchez (Repertorio Aranzadi 1.835/1980): ARTICULOS $14,35.1$ y DISPOSICION DEROGATORIA $3 .^{\mathrm{n}}$ DE LA CONSTITUCION.

\section{Principio de igualdad: probibición de la discriminación laboral por razón de sexo}

Por virtud de la disposición derogatoria tercera en relación con los artículos 14 y 35.1, todos ellos de la Constitución, debe entenderse derogado todo precepto que suponga una discriminación laboral por razón de sexo.

\section{Considerandos de la sentencia apelada:}

Constderando: $1 .^{\circ}$ Que en atención a lo manifestado por la recurrente, «Plastimetal, S. A.», en el Fundamento de Derecho B-2 de la demanda, es necesario advertir, primeramente, que la atribución conferida a los delegados provinciales de Trabajo para señalar cuáles sean los trabajos específicos del personal femenino (art. 75 de la Ordenanza de Trabajo para la Industria Siderometalúrgica de 29 de julio de 1970) no significa que la Dirección General, competente para conocer del recurso de alzada que pueda interponerse contra la resolución del órgano provincial, carezca de facultades, en la fase de impugnación administrativa, para hacer lo propio, pues la afirmación contraria equivale a negar aquel recurso en estos casos, tesis desprovista del menor apoyo legal (art. 122.1 de la Ley de Procedimiento Administrativo), sin que desde otro punto de vista pueda entenderse que existe incongruencia alguna en la resolución de la Dirección General al entrar al examen de la calificación de los trabajos sobre que versaba el expediente, pese a que las recurrentes en alzada se basaran en una motivación -improcedencia, a su juicio, de aplicar en caso alguno el coeficiente reductor después de dictado el Decreto de 20 de agosto de 1970, sobre derechos laborales de la mujer- no aceptada por la Dirección, y esto es así porque este órgano había de resolverse, en definitiva, las cuestiones planteadas en el expediente (art. 119 de la Ley citada) sin vinculación a los argumentos jurídicos invocados en las alegaciones hechas al recurrir en alzada.

2. Que el art. 75 de la Ordenanza mencionada ha de interpretarse a partir de la igualdad de los derechos laborales de la mujer respecto al hombre establecido en la L. 22 julio 1961, la cual está inspirada en el pleno reconocimiento de la capacidad de la mujer y cuya finalidad fue terminar con cualquier discriminación fundada en el sexo, con lo que se acogía, en el ámbito legislativo, el resultado de la evolución social habida en la conceptuación de la mujer referida a aspectos - políticos, profesionales, laborales- en los que en épocas pasadas se minusvaloró su participación o actividad, quiere decirse que el principio general entonces incorporado a nuestro ordenamiento jurídico fue, con todas sus naturales consecuencias, el de la igualdad entre ambos sexos, y no otra ha de condicionar en el futuro - como así viene aconteciendo, en efecto- la regulación de las particulares relaciones jurídicas en que la mujer se vea implicada.

3. Que en la línea expuesta se insertan, como no podía ser de otra manera, el citado precepto de la Ordenanza de Trabajo para la Industria Siderometalúrgica y lo prevenido en el D. 20 agosto 1970, de cuyo examen conjunto se siguen estas afirmaciones: a) La mujer tiene derecho a prestar servicios laborales en plena situación de igualdad jurídica con hombres y a percibir por ello idéntica remuneración; b) Las ordenanzas laborales no establecerán cláusulas que impliquen diferencia en las remuneraciones entre los trabajadores de uno y otro sexo; $c$ ) El trabajo realiza- 
do por el personal femenino, en la industria siderometalúrgica, tendrá idéntica retribución que el del personal masculino en los casos que dicho personal realice trabajos de igual clase y rendimiento, y d) En los demás casos - aquellos trabajos de distinta clase y menor rendimiento que los desempeñados por hombres - los delegados provinciales de Trabajo podrán señalar cuáles son los específicos del personal femenino, que serán remunerados aplicando el coeficiente reductor del 0,9 al salario del personal masculino.

4. Que la premisa ineludible para que determinados trabajos merezcan la calificación de «específicos del personal femenino» es que presenten unas características que los distingan de los desarrollados por varones $\mathrm{y}$, además, que el producto o utilidad que reporten al empresario sea inferior a aquellos que normalmente provienen de la mano de obra masculina, bien entendido que es inoperante por sí solo el dato de que sean desempeñados, de hecho, exclusivamente por mujeres, jugando únicamente en favor de la no calificación como femeninos la circunstancia de que se lleven a cabo corrientemente por hombres, y también ha de quedar claro que nuestra legislación ha superado la fase en que el trabajo de la mujer -aun prescindiendo de su clase y rendimiento- debía ser menos retribuido que el prestado por el varón, razón por la cual el coeficiente reductor establecido en el artículo 73 de la Ordenanza ha de obedecer a una paralela disminución del rendimiento laboral unida a circunstancias que permitan pensar que se trata de actividades particular o específicamente propias del sexo femenino.

5.० Que si se hace aplicación de lo anterior al caso debatido en este recurso pueden obtenerse las conclusiones siguientes: a) No se ha traído al proceso elemento de prueba alguno - ni de ello existe el menor indicio en el expediente administrativo- que permita apreciar que el rendimiento de los trabajos a que se pretende imponer el coeficiente reductor sea menor -al ser ejecutado por mujeres- del que se obtendría si se emplease mano de obra masculina, ni tampoco se ha ni siquiera alegado que se obtengan resultados en cualquier sentido deficientes, sino que, lejos de ello, se insiste -informe del ingeniero industrial don Julio M., presentado con la demanda, y del delegado provincial de Industria, traído el período probatorio- en las «cualidades intrínsecas de la mano de obra femenina» y en que «se requiere dotes de observación, minuciosidad y una especial sensibilidad a la captación de todos los matices que determinan la calidad», así como que es un trabajo que «se realiza con mucha más habilidad por el personal femenino porque normalmente la mujer tiene más agilidad en la manipulación de pequeños elementos», por todo lo cual sería paradójico, y hasta injusto, admitir que si las mujeres pueden ejercitar estos trabajos mejor que los hombres, percibieran salarios inferiores; b) Es, pues, erróneo sostener que con base en una mayor facilidad para desempeñar un trabajo o en que se trate, como informa el delegado de Industria, de alguno «muy adecuado para dar ocupación al personal femenino», pueda derivarse una disminución salarial, sino que, por el contrario, lo correcto es, dado que la mujer se ha incorporado a la vida laboral del país, que ésta desarrolle los trabajos más conformes a su sexo - la calidad de los cuales no dependerá de este único factor- y sea retribuida sin teducción alguna, y c) Del examen de los varios informes obrantes en el expediente y de los traídos a los autos se desprende que los trabajos de montaje y conjuntos parciales, repasado, plásticos y de verificación, a que se contrae el Suplico de la demanda, no constituyen un grupo que pueda clasificarse en ningún caso como de menor importancia - dentro del proceso general de fabricación - en relación a los demás desempeñados por mano de obra masculina, y aunque debe reconocerse que, en términos generales, requieren poco esfuerzo físico - en cuyo sentido podrían entenderse apropiados a la mujer-, no es éste, como bien indica la Dirección General de Trabajo en su resolución, el criterio exclusivo a que deba atenderse, ya que obviamente conduciría, separado de los 
restantes que han sido tenidos presentes, a que trabajos delicados e importantes pudieran ser retribuidos indebidamente.

6. Que, en resumen, entiende la Sala que para la aplicación del coeficiente reductor señalado en el artículo 75 de la Ordenanza es necesario: 1) Que se trate de trabajos de distinta clase y rendimiento de los desempeñados por varones, y 2) Que estas diferencias provengan de las peculiaridades del sexo femenino; rechazándose, por el contrario, toda interpretación que conlleve una reducción del salario de la mujer con fundamento en su sexo o, simplemente, en el menor esfuerzo físico requerido o en que se trate de una labor que le resulte más adecuada, sin tener en cuenta su efectivo rendimiento.

7. Que, consecuentemente, ha de ser desestimado el recurso contencioso-administrativo por ajustarse a derecho la resolución de la Dirección General de Trabajo objeto del mismo (artículo 83.1 de la Ley Jurisdiccional), sin que se observe la existencia de motivos que pudieran determinar una especial imposición de las costas causadas (artículo 131.1 de la misma Ley).

Considerandos del Tribunal Supremo:

Considerando: Que la brillante argumentación presentada para apoyar el recurso de apelación parte de que la clasificación de determinados trabajos como específicamente femeninos se basa en la naturaleza objetiva de la prestación, de la que se deriva una intrínseca distinción de aquéllos y justifica, por sí misma y no por razón del sexo de quien los lleva a cabo, distinta retribución a través de la aplicación del coeficiente reductor previsto en la Ordenanza que se cita en los «Vistos». Sin embargo, no puede desconocerse que en la resolución de la Dirección General de Trabajo, objeto de las pretensiones del recurso, se estableció categóricamente que ni bajo el punto de vista de la naturaleza ni bajo la perspectiva del rendimiento quedó acreditado que los trabajos en cuestión fueron sustancialmente distintos a los realizados por varones, atendiendo a diversos criterios de contraste, como esfuerzo físico, peligrosidad, atención y carácter repetitivo, a lo que aún ha de agregarse que esos indicios de menor rendimiento insinuados en el escrito de alegaciones de «Plastimetal, S. A.», tampoco han sido apreciados por el centro directivo, sin que, por su parte, la empresa haya conseguido desvirtuar tal apreciación inserta en un acto, que, como todos los precedentes de la Administración, lleva inherente la presunción de legalidad.

Considerando: Que es patente, por otra parte, el esfuerzo realizado por el centro directivo para acomodar la cuestión litigiosa al espíritu dimanante del Decreto de 20 de agosto de 1970 y al criterio restrictivo en cuanto a la discriminación salarial según la clase de trabajo, muy tempranamente establecido por la Sala IV de este Tribunal, cuya expresión más certera se encuentra precisamente en las argumentaciones que sustentan el fallo apelado. En esta perspectiva resulta difícil a esta Sala eludir aquel espíritu, mucho más acentuado a través de disposiciones, posteriores, desde luego, al planteamiento de la cuestión debatida, pero que, en definitiva, no han hecho sino concretarlo en torno a un principio que podría quizás ser expresado afirmando que no resulta accesible la categoría laboral de «trabajos específicamente femeninos» como fundamento de una reducción salarial. Así, bay que tener en cuenta, de una parte, el artículo 1.1.a) del Convenio 111 de la Organización Internacional del Trabajo de 25 de junio de 1958, ratificado por España el 26 de octubre de 1967, proscribiendo cualquier discriminación basada en motivos de sexo que tenga por efecto anular o alterar la igualdad de oportunidades o de trato en el empleo o en la ocupación; de otra, el artículo 10 de la Ley de Relaciones Laborales de 8 de abril de 1976, y por último, el juzgador actual debe imprescindiblemente tener en cuenta, por virtud del mandato interpretativo que 
dimana del artículo 3.1 del Código Civil y por virtud del imperativo que impone la tercera disposición derogatoria de la Constitución, lo dispuesto en los articulos 14 y 35.1 de ésta.

Considerando: Que esta orientación, determinada ya por textos positivos, no sería ni siquiera posible alterar la sentencia apelada; sin que, evidentemente, quepa reputar temerario el recurso de apelación.

\section{Comentario}

Destaca en esta sentencia la alusión a la disposición derogatoria tercera en conexión con los artículos 14 y 35.1, que tienen eficacia directa derogatoria sobre cualquier norma que suponga discriminación laboral por razón de sexo. Por otra parte, las argumentaciones de una y otra sentencias son irreprochables, llegando a idéntica conclusión, aludiendo la del Tribunal Supremo a la Constitución, a mayor abundamiento, pues en base a la legislación ordinaria y de la aplicación del Convenio 111 de la O. I. T. se alcanza igualmente el principio de igualdad que prescribe cualquier discriminación laboral por razón de sexo.

Núm. 5. Sentencia de 30 de mayo de 1980. Criminal. Ponente, A. Huerta y Alvarez de Lara (Repertorio Aranzadi 2.158/1980): ARTICULO 24 DE LA CONSTITUCION.

Derecho a obtener la tutela efectiva

de los jueces y Tribunales: limites

El derecho de las personas a obtener la tutela efectiva de los jueces y Tribunales en el ejercicio de sus derechos e intereses legítimos tiene como límite la utilización de una vía procesal que conduzca a una resolución favorable con perjuicio defraudatorio para el demandado.

Considerando: Que es principio fundamental de Derecho que toda persona puede ejercitar ante los Tribunales las acciones que la ley otorgue para la defensa de su derecbo, principio consagrado por la Constitución vigente, que en su artículo 24 establece que «todas las personas tienen derecho a obtener la tutela efectiva de los jueces y tribunales en el ejercicio de sus derechos e intereses legítimos, sin que en ningún caso pueda producirse indefensión», sin que ese derecho tenga otra limitación que la señalada por la jurisprudencia de esta Sala, que en sentencia de 12 de noviembre de 1975 declaró no ser moral ni lícito ni permisible en el ordenamiento del Estado de Derecho utilizar un proceso administrativo, civil o laboral para con plena conciencia de la falta de razón de lo que se postula, obtener una resolución favorable que lleve consigo un perjuicio defraudatorio para el demandado.

ConsIderando: Que sigue declarando esa misma doctrina jurisprudencial que no resulta jurídicamente superflua la concepción y apreciación de la estafa procesal como resultado de actuaciones seguidas ante jurisdicciones diversas, pues aunque no sea en principio admisible la idoneidad abstracta del proceso como medio de configurarla, sí cabe y es posible admitir su idoneidad concreta, cuando las maniobras preparatorias del mismo y las torticeramente empleadas en su tramitación y desarrollo presentan un grado de similitud suficiente para engañar, hacer ineficaces los medios de control del órgano jurisdiccional y determinar que el juzgador sea 
razonablemente persuadido a pronunciar una decisión así predeterminada, de la que sobreviene un perjuicio económico para el demandado con equivalente y correlativo beneficio del actor, como reiteradamente ha venido declarando la más moderna doctrina de esta Sala, de las que son claramente significativas las sentencias de 10 de marzo de 1960, 3 de octubre de 1967, 7 de octubre de 1972, 2 de octubre de 1974, 12 de noviembre de 1975, 19 de abril de 1976 y 25 de octubre de 1978.

Considerando: Que de las declaraciones de hecho formuladas en la sentencia recurrida que por no haber sido desvirtuadas ni impugnadas debidamente conservan todo su valor esencial, aparece completamente delineada de conducta seguida por los dos procesados entre los cuales no nos dicen los hechos probados que hubiera acuerdo previo de voluntades, unidad de acción y mutuo consenso; así que sentado esto procede examinar por separado la conducta seguida por los dos procesados.

Considerando: Que de la citada relación histórica aparece que el procesado Manuel G. A., dueño de la mitad proindivisa de la mina de hulla denominada «La Mora Primera», que se hallaba sin explotar, después de varias conversaciones en su casa, estando presente su esposa, la vendió en documento privado al querellante, haciendo constar expresamente en dicho documento que contaba con el consentimiento de su esposa, sin que cuando ésta, cuatro meses después, presentó contra los dos contrayentes papeleta de conciliación alegando su falta de consentimiento a lo pactado, el marido se allanara a tal pretensión, sino que contrariamente, dando por lícita la convención efectuada, realizó todas las gestiones para la efectividad del contrato, entregando al comprador la cosa vendida, la que puso en su poder y posesión, cumpliendo de ese modo con lo pactado e impuesto en los artículo 1.461 y siguientes del Código Civil, que regulan las obligaciones del vendedor, siendo por consiguiente su conducta conforme a Derecho, por lo que no se le puede imputar por sus actos ningún ilícito penal y punible.

Considerando: Que tampoco es antijurídica la conducta seguida por la procesada, Manuela A. G., al intentar contra los referidos contratantes acto de conciliación alegando su falta de consentimiento a lo pactado, pues ello no constituye, por la propia naturaleza y finalidad del instituto procesal de la conciliación, una estafa procesal, ni la estafa genérica del número $10^{\circ}$ del artículo 529 del C. P. ni siquiera del artículo 533 en grado de tentativa, ni, por otro lado, consta que no fuera por su propio y voluntario desistimiento el dejar de formular en el juicio declarativo correspondiente demanda de nulidad del contrato por falta de consentimiento, ni de la relación fáctica aparece el uso de maniobras engañosas con propósito defraudatorio, y menos que la pretensión que contenía la papeleta de conciliación fuera capaz de inducir a error al juez y a la contraparte en este acto ni en el declarativo que en su día hubiese podido formular, al no constar los fundamentos de hecho y derecho y en que se propusiera apoyar esa pretensión, ni en el ardid de que se iba a valer para engañar o intentar engañar al órgano jurisdiccional; por otro lado, el que estuviera presente la esposa en varias de las conversaciones sostenidas en su casa por el marido con el futuro comprador implica ardid engañoso, pues el silencio no puede valer como declaración de voluntad, salvo en determinadas condiciones que cabe interpretarlo como tácita manifestación de consentimiento, condiciones que no concurren en el caso enjuiciado, en el que el precio de la venta se determinó definitivamente fuera de su presencia, todo lo cual, unido a los ajustados razonamientos que se hacen en la sentencia recurrida, conduce a la desestimación del único motivo del recurso, amparado en el número $10^{\circ}$ del artículo 849 de la L. E. Criminal. 


\section{B) Resoluciones de la Dirección General de los Registros}

\section{R. 3. Resolución de la Dirección General de los Registros y del Notariado de 8 de mayo de 1980 (Repertorio Aranzadi 1.996/1980): ARTICULOS 14 y 39 DE LA CONSTITUCION.}

Igualdad ante la Ley de los bijos

Conforme a esta resolución, los artículos 14 y 39 de la Constitución no son de directa aplicación, por lo que hasta tanto no se modifiquen los preceptos del Código Civil, así como los correspondientes que regulan el Registro Civil, no son equiparables los hijos matrimoniales a los no matrimoniales.

Considerando: Que, cualesquieta que sean las irregularidades cometidas en las inscripciones de nacimiento de los tres hermanos, lo cierto es que de ellas, de la inscripción de la defunción del marido de la madre y de la del matrimonio de éstos, resulta que la madre estaba casada al tiempo de la concepción de esos tres hijos.

Considerando: Que el principio constitucional de equiparación de los bijos y el principio del Convenio de Roma de respeto a la vida familiar no son suficientes por sí para entender reformados los preceptos sobre acceso al Registro de una filia. ción paterna extramatrimonial de bijo nacido de mujer casada, pues el carácter estricto y formal de las normas aplicables, los encontrados intereses en juego cuya decisión es propia de un procedimiento judicial, la eficacia que, en relación con la determinación de la filiación paterna, debe tener el matrimonio mismo en armonia con el principio, también constitucional, de protección de la familia y los términos de futuro con que la Constitución se refiere a la investigación de la paternidad, impiden una precipitada y problemática asimilación del reconocimiento paterno de bijo babido con casada con el de bijo babido con soltera.

Considerando: Que, consiguientemente, y sin necesidad de examinar otros posibles obstáculos, hay que concluir que no es inscribible la filiación natural paterna pretendida, ya que el padre, aunque no estuvo casado, no podía contraer matrimonio al tiempo de la concepción de los hijos con la que figura como madre (cfr. artículos 119 del C. Civil y 187 del Reglamento del Registro Civil).

Considerando: Que, con arreglo a los artículos 98 de la Ley del Registro Civil y 371 de su Reglamento, es gratuito el expediente y también el recurso entablado, al no apreciarse temeridad en el recurrente.

\section{Comentario}

Es más que dudoso que el principio de igualdad de los hijos, con independencia de su filiación, no sea de directa aplicación, así como que la inaplicación del mismo se fundamente en el principio de protección de la familia. A nuestro juicio, el artículo 39.2, en su punto primero, en conexión con el artículo 14 de la Constitución, crea directamente un derecho en los hijos sea cual sea su filiación, derecho que no cede ante el principio programático de la protección de la familia, que precisa ser desarrollado por ley. En consecuencia, no parece necesario esperar a la reforma del Código Civil (que está a punto de culminar en esta materia cuando se redactan estas líneas), lo que no significa que el ejercicio del derecho. no presente dificultades técnicas considerables.

Por lo demás, se sigue en esta resolución la doctrina del Auto de 26 de noviembre de 1979, que tuvimos oportunidad de comentar en otro lugar (véase núm. 15 del Repertorio de 1979 en el núm. 6 de esta Revista). 